\title{
Enhancing building information modelling (BIM) training in Nigerian polytechnics: towards sustainable development in Southeast Nigeria
}

\author{
Udochukwu Marcel-Okafor ${ }^{1, *}$, and Marcellinus Okafor $^{2}$ \\ ${ }^{1}$ Department of Architectural Technology, Federal Polytechnic Nekede, Imo State Nigeria, Nigeria \\ ${ }^{2}$ Department of Architecture, Imo State University Owerri, Imo State Nigeria, Nigeria
}

\begin{abstract}
Architectural technology practice in Nigeria is influenced on the one hand by the drive to adopt technologically advanced techniques aimed at providing solutions to the existing challenges within the built environment, and on the other hand by constantly emerging socio-economic variables associated with high population growth, urban migration and resultant housing demands. From the outset of the drawing proposal to the entire lifespan of buildings, innovative developments in building information modelling (BIM) have enabled architectural technologists attain sustainable feats in the building industry. This study examined the curriculum for BIM training in polytechnics domiciled in Southeast Nigeria and the impact on sustainable development practice within the region. Sixtythree (63) architectural firms and three (3) polytechnics were randomly selected for this study. The survey research design was adopted in this study: two sets of structured questionnaires were administered to architectural technology graduates and their employers. 130 copies of questionnaire were administered to graduates of the institutions. The study revealed that $96 \%$ of the graduates had acquired some level of BIM proficiency; 56\% acquired it from school, while $40 \%$ indicated it was acquired in practice after graduation. The result of correlation analysis showed that correlation between practice performance of technologists and proficiency in BIM is significant $(p<0.01)$. The results of regression coefficients showed that proficiency in BIM had significant correlation with practice performance of the graduates. The study showed that course contents for courses in computer application did not extensively provide opportunities for graduates to acquire relevant skills. A robust review of the curriculum is needed to produce technically efficient technologists that can tackle the demands of the built environment for sustainable development to thrive.
\end{abstract}

\section{Introduction}

Unless housing is sustainable, the society remains unstable and in discord with nature [1]. Nigeria is the most populated nation in sub-Saharan Africa with a population of over 200 million people and a projected annual growth rate of $2.6 \%$ [2]. The country, as a member of

\footnotetext{
* Corresponding author: uosmarcelokafor@yahoo.com
} 
the United Nations (UN), resolved to achieve milestones in sustainable development activities. However, the UN report of an estimated housing shortfall of over 17 million units and over 100 million Nigerians living in substandard housing presents conspicuous challenges to the building industry [3]. Equally critical is the fact that Nigeria has not recorded any noteworthy milestone targeted at ameliorating the housing shortages [4; 5]. This raises deep concerns for both architectural technology education and professional practice which remain at the centre of service delivery in the building industry. The Southeast zone of the country is the area of study. The zone accounts for $3.2 \%$ of the national landmass with a population of approximately 16 million people representing about $12 \%$ of the entire national population [6]. The zone features the highest population densities and widest spread of urban migration growth in the country, which helps to explain the plethora of challenges associated with the built environment that besiege the zone. Advanced building technologies like mass production of pre-fabricated building types, which target efficient mass housing delivery have not been harnessed, as approximately nine (9) out of ten (10) buildings in Nigeria are still built in-situ using sandcrete blocks [7]. This means that the relevant innovative building technologies that drive down cost and encourage production of affordable mass housing units that are urgently needed in the Nigerian situation are not explored generally.

Architectural technology programme in Nigeria is exclusively offered in polytechnics and colleges of technology. The NBTE, an acronym for National Board for Technical Education was inaugurated by the Federal Government of Nigeria to explicitly regulate all aspects of technical and vocational education that fall outside university education. The outlined NBTE education course curriculum and specification is used as a benchmark for standardising the academic course contents of courses being offered in these technical institutions [8]. However, scholars have expressed concerns regarding the suitability of the document, for addressing the dynamic human and societal needs in Nigeria $[9 ; 10 ; 11 ; 12]$. The Government owned polytechnics domiciled in each of the five states that make up the Southeast zone offer NBTE-accredited architectural technology programme as shown in Table 1.

Table 1.Polytechnics that offer architectural technology programme in Southeast Nigeria

\begin{tabular}{|c|c|c|c|c|}
\hline Name of Institution & Location & $\begin{array}{c}\text { Date of } \\
\text { Establishme } \\
\text { nt }\end{array}$ & $\begin{array}{c}\text { Date HND } \\
\text { architecture } \\
\text { programme } \\
\text { commenced }\end{array}$ & $\begin{array}{c}\text { Owner- } \\
\text { ship }\end{array}$ \\
\hline $\begin{array}{c}\text { Institute of Management and } \\
\text { Technology, Enugu State }\end{array}$ & $\begin{array}{c}\text { Enugu } \\
\text { State }\end{array}$ & 1973 & 2002 & State \\
\hline $\begin{array}{c}\text { Federal Polytechnic, Nekede, } \\
\text { Owerri, Imo State. }\end{array}$ & Imo State & 1978 & 1982 & Federal \\
\hline $\begin{array}{c}\text { Akanu Ibiam Federal } \\
\text { Polytechnic, Unwana-Afikpo, } \\
\text { Ebonyi State. }\end{array}$ & $\begin{array}{c}\text { Ebonyi } \\
\text { State }\end{array}$ & 1981 & 1985 & Federal \\
\hline $\begin{array}{c}\text { Federal Polytechnic Oko, } \\
\text { Anambra State }\end{array}$ & $\begin{array}{c}\text { Anambra } \\
\text { State }\end{array}$ & 1982 & 1987 & Federal \\
\hline $\begin{array}{c}\text { Abia State Polytechnic, Aba, } \\
\text { Abia State. }\end{array}$ & Abia State & 1992 & 2008 & State \\
\hline
\end{tabular}

The aim of this study is therefore, to assess the level of BIM training architectural technologists received in school and the effect on their practice performance. To achieve this aim, the study investigated the course contents of computer courses offered in NBTEaccredited architectural technology departments of polytechnics in Southeast Nigeria and the practice performance of graduates of the schools. The results of this empirical study would on the one hand, draw attention to areas of the curriculum that require urgent overhaul necessary to attain such developmental target through emphasis on BIM applications. On the 
other hand, the results would be beneficial to both regional as well as national development as part of solution strategies for mass housing needs. Furthermore, the results would highlight the prospects and constraints of architectural technology programme in Nigerian polytechnics in order to enable practitioners, professionals, educators and stakeholders make feasible decisions concerning the right course of action beneficial to Nigerian technological advancement agenda for sustainable development to thrive in the society.

\subsection{Literature review}

A pertinent issue in architectural education has been the nexus between what is taught in schools and the skills required for practice $[13 ; 14 ; 12]$. Computer Aided Design and Draughting (CADD) is the use of computer programmes to generate two or three dimensional (2D or 3D) clear and detailed illustrations of objects. The transition from traditional drawing tools to the use of CADD has affected the trajectory of training relevant for the architectural technologist. Particularly, since advances in CADD such as building information modelling (BIM) have accentuated the roles architectural technologists play in providing sustainable development within the built environment $[15 ; 16 ; 17]$.

As an extensive approach to design, construction and procedures in the building industry, BIM contains broad spectrum of models, tools and workflows which are essential to be learned and applied by professionals in the industry [18]. In addition, implementation of BIM has the potential to expunge wastages, challenges arising from discordant relationships among professionals that may hinder work progress, as well as create dexterity at design and construction stages [19]. BIM presents robust potential to reform methods of design conception, development, and actualisation of modern structures [20]. Proficiencies with BIM applications hold an indispensable opportunity for technological advancement in the building industry.

Architectural technology is constantly evolving, consequently the relevance accorded historic and contemporary context will continuously evolve especially with the everincreasing professional diversity within the programme [21]. Prof. Sam Allwinkle, Chair of the chartered institute of architectural technologists (CIAT) Education Board, defined architectural technology as the technology of architecture and endorsed architectural technology professional practice and discipline as integral to details and detailing [22]. [23] proposed a viewpoint that sought to define architectural technology profession and the training process involved, with emphasis on detail design. [24] stated that the developments of BIM have been beneficial to a particularly tedious, precarious and controversial industry. [25] revealed that over $75 \%$ of the architectural technology community agreed with CIAT's description of the profession as a varied inclusion of different components, wherein science, engineering, form, function and fabric all actively combine in defining the profession.

There have been concerted efforts to align architectural technology practice in Nigeria with contemporary practice of ICT-driven economies by adopting technologically advanced approaches aimed at providing solutions to the existing challenges within the built environment. Studies also revealed that because architectural practice in Nigeria has been largely computerised, only the graduates proficient in CADD are relevant and employed. [26] stated that the technological changes especially in information and communication technology (ICT) as well as the rise in complex building designs have necessitated the use of computers. Nonetheless, studies have shown numerous problems that impede effective implementation of CADD in schools $[27 ; 28 ; 29 ; 30 ; 31 ; 32 ; 33$ ]. [34] however, observed that the paucity of conversation and empirical data of prevailing building technology brought to light barriers to advancements in sustainable building technologies. [35] revealed that specific tools taught had direct link to the area of curriculum with the discipline, noting that 
AutoCAD/Photoshop and Revit were taught to architecture and architectural technology students, who displayed exceptional abilities in adapting to the BIM software applications.

\section{Methods}

The survey research design was adopted in this study. Structured questionnaire was used to elicit data from the respondents that comprised the academic staff in the departments, the architectural technologists that graduated from the schools and are in active professional practice and the architectural firms that employ these graduates within Southeast Nigeria. Based on the forgoing, this study adopted the format of the evaluation stated in the literature [36] in the following format:

- The data on CADD proficiency was a three point rating scale: 1-none (no technical mastery of software package), 2-basic proficiency (elementary technical mastery of software package), 3-expert proficiency (full technical and creative mastery of software package).

- The data variables on relevance of the course contents was evaluated on a five point likert scale: 1-strongly disagree, 2 -disagree, 3 -uncertain, 4-agree, 5-strongly agree.

The study is comprised of three (3) research populations namely: five (5) polytechnics that offer NBTE- accredited architectural technology programmes and are spread across the five states that make up Southeast zone; architectural technologists that graduated from the institutions and are in professional practice; and their employers in registered architectural firms domiciled within the zone. As a result of the heterogeneous structure of ownership of the polytechnics, it became expedient to adopt a stratified sample of polytechnics. Hence, two (2) homogenous groups comprising the State-owned institutions and the Federal owned institutions were derived. Subsequently, polytechnics were randomly selected from a stratified sample of polytechnics in the ratio 1:2 for the State and Federal owned schools.

From the pilot survey conducted to observe the number of HND graduates from each school in each year spanning six (6) years, the total number of HND graduates was 358 graduates which formed the population size ' $\mathrm{N}$ '. To determine the size of the sample $(n)$ from the research population of the graduates, the study adopted the approach based on precision rate and confidence level which availed it of a mathematical solution for determining ' $n$ ' [37]. Hence using the Yamane's simplified formula to calculate sample size with $95 \%$ precision level, the sample size was determined as follows:

$$
n=\frac{\mathrm{N}}{1+\mathrm{N}(\mathrm{e})^{2}}
$$

Where; $n$ is the sample size, $\mathrm{N}$ is the population size, and e is the level of precision. However, not all the graduates are working in firms within the study area and not all are working under ARCON registered firms. Hence, an assumption of 50\% of the total number of HND graduates (179 graduates) is used to determine the population size 'N'. Applying the above formula as follows;

$$
n=\frac{179}{1+179(.05)^{2}}=\frac{179}{1.4475}=123.661 \approx 124
$$

Hence, 124 copies of questionnaire representing the sample size, were supposed to be administered to the technologists, however, with an allowance of 5\% given for envisaged low response, a total of 130 copies of the questionnaire were administered to the HND graduates in practice within the five states that constitute the study area. This was done according to first contact basis which was obtained from the list of graduate members registered with the respective state chapters of the Nigerian Institute of Architects (NIA), and some were sent as softcopies via their email address. 
The size of the sample ( $n$ ) for this third research population (the employers) was based on desired accuracy with a population percentage or variability of $50 \%$, confidence level of $95 \%$, and a 5\% margin of error [38] in [39]. Gill et al. [38] presented sample size appropriate for specified permutations of precision, confidence levels and a population percentage or variability of 50\%. Hence, the study adopted 63 ARCON registered architectural firms as the sample size. However, owing to the uneven spread of the firms across the study area, copies of the questionnaire were randomly administered to 3 firms in Abia State, 5 firms in Anambra State, 43 firms in Enugu State and 12 firms in Imo State.

The data collected were analysed at three levels: the univariate level which involved frequency distribution analysis using descriptive techniques. The second level was the bivariate analysis, wherein the correlations amongst the variables were established. The third and final level was the multivariate, wherein regression analysis was carried out.

\section{Results}

Basic data related to the respondents as academic staff of the respective departments and lecturers of the students that graduated were obtained and presented in this section. The extent of the responses across available categories were specified as aggregated data obtained from the departments of the sampled Polytechnics and presented in percentages (\%) as follows:

The results of analysis on aggregated data on Name of Polytechnic (NOP) revealed that the largest proportions of the respondents were drawn from Federal Polytechnic Oko, Anambra State; this was closely followed by respondents drawn from Federal Polytechnic Nekede, Imo state. The results showed that the least proportion of the respondents was drawn from Abia State Polytechnic Aba as illustrated in Figure 1. This reflects factual responses from the department in the respective Polytechnics and not necessarily the staff strength spread across the three departments.

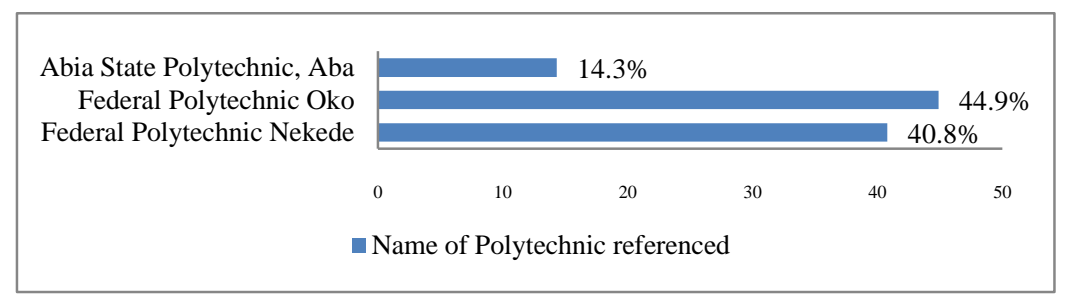

Fig. 1.Name of Polytechnic referenced

The results of analysis on aggregated data on Academic qualification of staff (AQS) revealed that the largest proportion of the respondents $(63 \%)$ were composed of academic staff with Master of Science (M.Sc.) degree, this was closely followed by Higher National Diploma (HND) certificate holders and Doctor of Philosophy (Ph.D.) degree that represented close to $17 \%$ and $13 \%$ of the respondents respectively. The results showed that the least proportion of the respondents which comprised $7 \%$ of the total proportion was made up of academic staff with only Bachelor of Science (B.Sc.) degree. This is illustrated in Figure 2. 


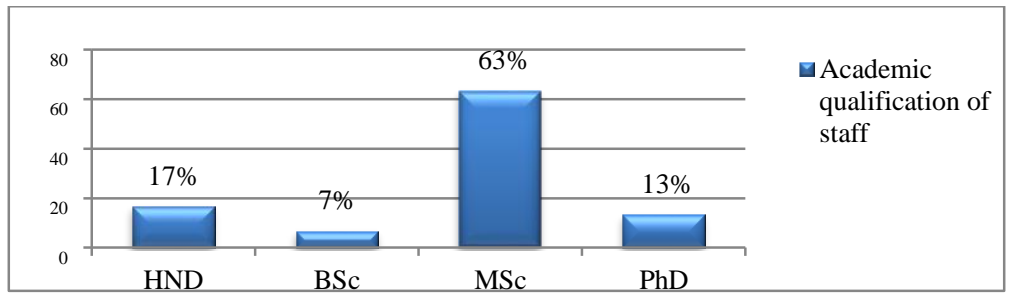

Fig. 2.Academic qualification of staff

From the results of the analysis of aggregated data on Relevance of course contents in computer courses $(R C C P)$ revealed that two-thirds $(66.6 \%)$ of the respondents agreed that the course contents in Computer courses are relevant to practice. However, the remaining one-third of the respondents comprised the group that were uncertain about the relevance of the course contents and the group that disagreed on the relevance of course contents in computer courses to practice as illustrated in Figure 3.

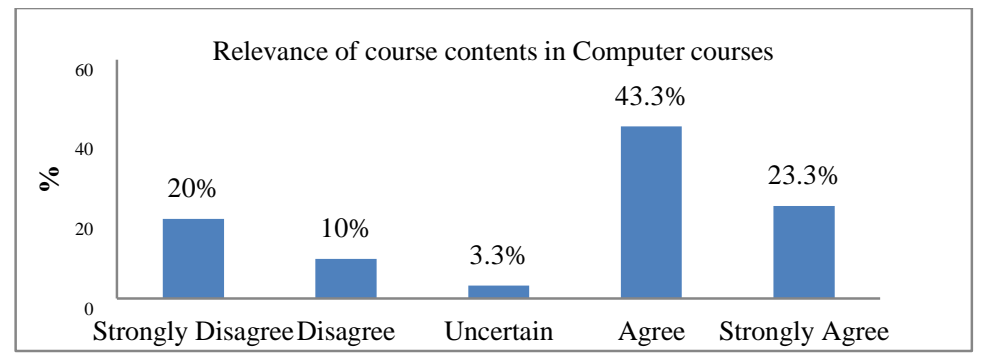

Fig. 3.Relevance of course contents in Computer courses

The results of the analysis of aggregated data on Need to improve curriculum contents of computer courses (NICC) revealed that the largest proportion of the respondents $(93.4 \%$ ) agree that the course contents of computer courses require improvement. The remaining proportion of respondents was either uncertain or disagreed that the contents require improvement. Further results of analysis showed that more than two-thirds of respondents $(69 \%)$ were of the view that the software packages used for computer courses taught in the HND programme were not adequate. Preponderance of the respondents (93.3\%) affirmed the need for more software packages to be used in teaching computer courses.

Data related to the respondents as employers of the graduates were specified as aggregated data obtained from the sampled architectural firms and presented in percentages $(\%)$ as follows:

The results of the analysis of data on Style of Studio draughting in the firms showed that over two-thirds of the firms where the respondents practiced, operated with solely contemporary computer workstations, while the remaining proportion of respondents which constituted less than one-third of the total proportion practiced in firms that adopted both the traditional drawing tables and computer workstations as style of draughting in the studios as shown in Figure 4. This revealed a general shift in favour of the contemporary style of studio draughting amongst the architectural firms where the respondents practiced. 


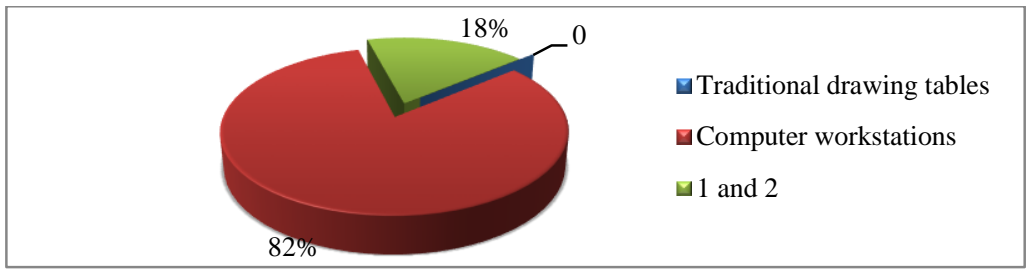

Fig. 4.Style of Studio Draughting in the Firms

The results of aggregated data on Criteria for employing architectural technologists ( $C F E$ ) show that more than two-thirds of respondents (80.3\%) considered both the certificate and proficiency in Computer Aided Design and Draughting (CADD) as qualifying criteria for employing the technologists. However, the remaining proportion which was less than one-third of the respondents comprised of those that considered the HND certificate alone (4.9\%) as the qualifying criteria for employing the technologists, those that considered proficiency in CADD alone (1.6\%), as well as those that considered other attributes such as strength of oral communication among others in addition to certificate and CADD proficiency $(13.1 \%)$ as qualifying criteria for employing the technologists.

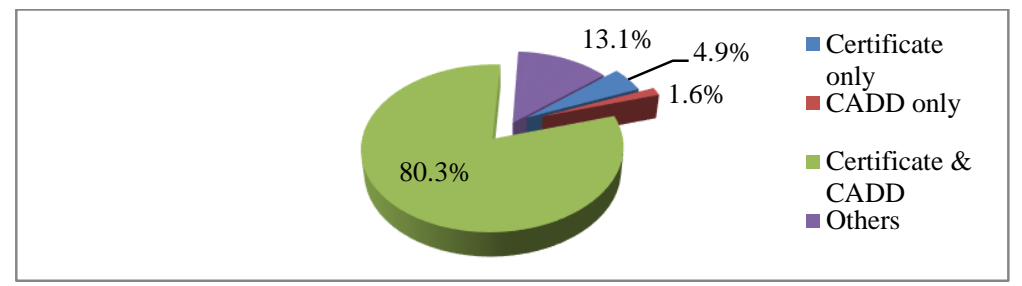

Fig. 5.Criteria for Employing the Architectural Technologists in the Firms

The results of aggregated data on Graduates' proficiency in using AutoCAD (PAU) showed that close to two-thirds of the respondents stated that the employed graduates exhibited basic proficiency in the use of AutoCAD. Close to one-third of the respondents reported that the graduates displayed expert proficiency in using the application. However, the remaining proportion of the respondents which was not up to one-tenth of the total respondents were of the view that the employed graduates did not display proficiency in the use of the software application as shown in Figure 6.

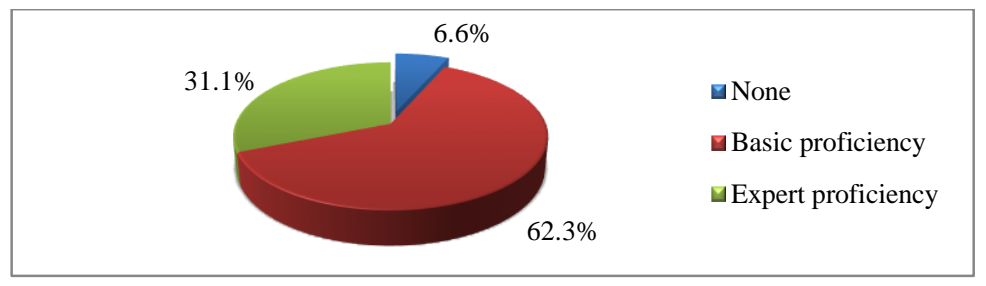

Fig. 6.Graduates' proficiency in using AutoCAD

The variable Graduates' proficiency level in using ArchiCAD (PAR) was investigated. Results revealed that more than half of the respondents $(54.1 \%)$ stated that the employed graduates exhibited basic proficiency in the use of ArchiCAD, while less than half of the respondents $(41 \%)$ reported that the employed graduates displayed expert proficiency in using the application. However, the least proportion comprised barely one-twentieth of the 
respondents $(4.9 \%)$, were of the view that the graduates employed did not demonstrate proficiency in the use of the application. This is shown in Figure 7.

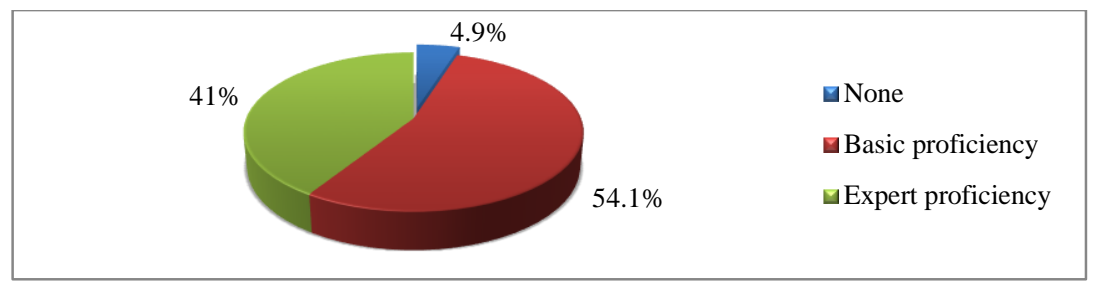

Fig. 7.Graduates' proficiency in using ArchiCAD

The results of analysis of aggregated data on Graduates' proficiency level in using Revit (PRE) showed that close to half of the respondents $(47.5 \%)$ stated that the graduates employed exhibited basic proficiency, while $34.4 \%$ displayed expert proficiency in the use of Revit. Close to one-fifth of the respondents that remained were of the view that the graduates employed did not display any proficiency in the use of the software application as illustrated in Figure 8.

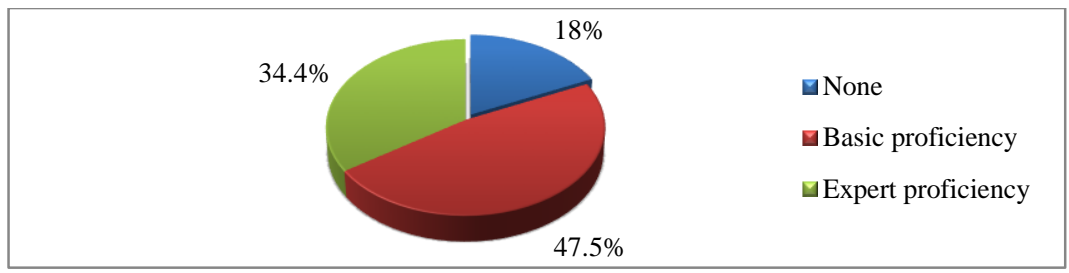

Fig.8. Graduates' proficiency in using Revit

At the bivariate analysis, two weighted variables: Practice performance of technologists (PPT) and Proficiency in CADD software (PCS) were investigated and Spearman Rho correlation analysis tool was used to test the significant relationship. The result of analysis showed that correlation between the variables is significant $(\mathrm{p}<0.01)$ as illustrated in Table 2.

Table 2. Spearman Rho correlation analysis of relationship between Practice performance of technologists (PPT) and Proficiency in CADD software (PCS)

\begin{tabular}{|l|l|l|}
\hline \multicolumn{2}{|c|}{} & Proficiency in CAD software \\
\hline Practice performance of students & Pearson Correlation & $.371^{* *}$ \\
\cline { 2 - 3 } & P-Value & .003 \\
\cline { 2 - 3 } & $\mathrm{N}$ & 61 \\
\hline
\end{tabular}

* Correlation is significant at the 0.01 level (2-tailed)

For the regression analysis of Practice performance of graduates, the categorical regression (CATREG) analysis tool was used to investigate the interactions between the dependent variable Practice performance of graduates and the following independent variables; Proficiency in using AutoCAD (PAU); Proficiency in using ArchiCAD (PAR);

Proficiency in using Revit (PRE) thereby characterise their relationship. The variables were introduced using the forced entry method into the model. The results revealed those whose contributions were significant in affecting the dependent variable. The result of the model summary as illustrated in Table 3 showed that the model explains $49.2 \%$ of the residual variation $(\mathrm{R} 2=.492, \mathrm{R} 2$ Adjusted $=.348)$ 
Table 3. Model Summary for dependent variable Practice Performance of graduates

\begin{tabular}{|c|c|c|c|c|}
\hline \multicolumn{5}{|c|}{ Model Summary } \\
\hline & $\begin{array}{c}\text { Multiple } \\
\text { R }\end{array}$ & $\begin{array}{c}\text { R } \\
\text { Square }\end{array}$ & $\begin{array}{c}\text { Adjusted R } \\
\text { Square }\end{array}$ & $\begin{array}{c}\text { Apparent } \\
\text { Prediction } \\
\text { Error }\end{array}$ \\
\hline Standardized Data & .701 & .492 & .348 & .508 \\
\hline
\end{tabular}

The results for ANOVA were likewise outputted for the entry of variables as illustrated in Table 4. The results of the analysis showed that there was significant correlation of dependent variable with all independent variables collectively. $(F(13,46)=3.425, p<0.5)$

Table 4. ANOVA results for dependent variable Practice Performance of graduates

\begin{tabular}{|c|c|c|c|c|c|}
\hline \multicolumn{7}{|c|}{ ANOVA } \\
\hline & Sum of Squares & df & Mean Square & F & Sig. \\
\hline Regression & 29.513 & 13 & 2.270 & 3.425 & .001 \\
\hline Residual & 30.487 & 46 & .663 & & \\
\hline Total & 60.000 & 59 & & & \\
\hline
\end{tabular}

The results of regression coefficients revealed the level of significance of each individual variable. As shown in Table 5, the independent variable Proficiency in using ArchiCAD (PAR) was found to have significant correlation with Practice Performance of graduates.

Table 5. Regression Coefficients table for Practice Performance of graduates

\begin{tabular}{|c|c|c|c|c|c|}
\hline \multicolumn{6}{|c|}{ Coefficients } \\
\hline & \multicolumn{2}{|c|}{ Standardized Coefficients } & \multirow[b]{2}{*}{ df } & \multirow[b]{2}{*}{$\mathbf{F}$} & \multirow[b]{2}{*}{ Sig. } \\
\hline & Beta & $\begin{array}{l}\text { Bootstrap (1000) } \\
\text { Estimate of Std. } \\
\text { Error }\end{array}$ & & & \\
\hline Proficiency in using AutoCAD & .178 & .117 & 2 & 2.318 & .110 \\
\hline Proficiency in using ArchiCAD & .209 & .107 & 2 & 3.809 & .029 \\
\hline Proficiency in using Revit & .112 & .147 & 2 & .585 & .561 \\
\hline
\end{tabular}

\section{Discussions}

The result of the analysis showed that correlation between practice performance of technologists (PPT) and proficiency in CADD software (PCS) is significant $(\mathrm{p}<0.01)$. The implication is that practice performance of technologists within the study area increased with increase in proficiency in CADD software. It also supports the results of correlations presented by Hamma-Adama and Kouidder (40) and the standpoint that the higher the software sophistication, the higher the proficiency level of training received and acquired by students. The aggregated data findings on variables: Proficiency in using AutoCAD (PAU); Proficiency in using ArchiCAD (PAR) and Proficiency in using Revit (PRE) which represented graduates' proficiencies in computer software applications revealed that the larger number of graduates exhibited basic proficiency in all three software packages used in the assessment. This supports the standpoint that specific tools taught were directly connected to the area of curriculum with the discipline (35). The implication is that the curriculum contents of computer courses taught were not comprehensive and focused on basic aspects of the applications.

Furthermore, the area-wise analysis of graduates' overall proficiency in using AutoCAD revealed that $62.3 \%$ of the graduates displayed basic proficiency and $31.1 \%$ displayed expert 
proficiency. The area-wise analysis of graduates' overall proficiency in using ArchiCAD showed that $54.1 \%$ of the graduates displayed basic proficiency and $41 \%$ displayed expert proficiency. The results of area-wise analysis of graduates' overall proficiency in using Revit showed that $47.5 \%$ displayed basic proficiency and $34.4 \%$ displayed expert proficiency. However, a notable $18 \%$ of the graduates displayed no proficiency in using Revit. The implication is that a preponderance of graduates displayed expert proficiency in using ArchiCAD, while majority also displayed basic proficiency in using AutoCAD. This is in agreement with findings of correlations between use of CAD in design studio/assignments and attained CAD proficiency amongst students in (32).

\section{Conclusion}

The architectural technologist works within a sector characterised by constantly evolving technical developments on the one hand and equally emerging socio-economic demands of a dynamic society on the other hand. There is no gainsaying the need to upgrade the housing stock in the country in the light of the sustainable development goals. The curriculum of architectural technology programme must therefore target advanced digital design and construction solutions in order to remain relevant and suitable for emerging social, economic and cultural needs within the Nigerian milieu. The HND polytechnic graduate of architectural technology is exposed to a discipline that has moved away from the traditional role of draughtsmanship to embrace new roles defined by technology, science and ICT applications. Research findings have revealed that graduates still perform within the parameters of the HND programme, as stated in the NBTE curriculum course and specification. The findings also revealed that $54.1 \%$ of the graduates exhibited basic proficiency in the use of ArchiCAD and $41 \%$ exhibited expert proficiency, which is a reflection of level of training acquired and supports the view that advanced software sophistication results in greater proficiency level of training (40). With increased prominence accorded building information modelling (BIM) tools, it is expedient that the entire academic process encompassing curriculum, students and, learning environment be ICT-compliant.

\section{References}

1. B. Edwards, Sustainable housing principles \& practice, 12 (Taylor \& Francis, 2005)

2. Worldometer. Retr Dec 2020 frm Afr. Count, pop. www.worldometer.info

3. World Bank. Retr 2019 documents, worldbank.org

4. A. O. Olotuah, A. A. Taiwo, IISTE, 5(16), 1 (2015)

5. F. Akeredolu, Retr Dec 22 2019, africa.com: https://www.africa.com

6. National Bureau of Statistics (Abuja, 2014).

7. A. A. Raheem, A. K. Momoh, A. A. Soyingbe, Int'l J. of Sust. Const. Eng. 3(1) , (2012)

8. National Board for Technical Education (NBTE) Retr 2017 www.nbte.gov.ng

9. Abubakar, AARCHES J. 6(1), 52 (2007)

10. P. O. Adewale, O. O. Adhuze, Front. Archit. Res. 3(1),69 (2013)

11. A. Oluwatayo, P. Aderonmu, I. Ezema, CIB W107 2014 Int'l Conf., 637 (2014)

12. A. P. Opoko, A. A. Oluwatayo, Arts and Design, 8,24 (2015)

13. R. Gutman, J. Archit. Edu, 24 (1987)

14. A. Tzonis, Front. Archit. Res 1(3), 76 (2014)S. Emmit, Architectural technology (John Wiley \& Sons, London, 2009) 
15. G. Armstrong, D. Comiskey, A. Pepe, $4^{\text {th }}$ ICAT, 1 (2013)

16. G. Armstrong, S. Allwinkle, $51^{\text {st }}$ Int'l Conf. Archit. Sc. Ass., 803 (2017)

17. B. Succar, W. Sher, AUBEA2013 (2013)

18. R. Eadie, M. Browne, H. Odeyinka, C. Mckeown, Blt. Env. Proj. Ast. Mgt., 5(1) 4 (2015)

19. E. Solomon, http://seaony.org/publications/files/SEAoNY-Vol12-01

20. UK Quality Code for Higher Education Retr 2018 www.qaa.ac.uk/aboutus/glossary

21. CIAT. https://ciat.org.uk>a-u>what-is-a-chartered-architectural-technologist.html

22. F. Robertson, S. Emmitt, ICAT '16, 1(2016)

23. P. L. Caplehorn, J. Blding Surv., Appr. \& Val, 5(4) , 302 (2017)

24. A. Mahdmina, T. Hamid, S. Zulu, 7th Int'l Cong. Archit Techn. , 6 (2018)

25. M. E. Abdulrahman, L. A. Lawal, AARCHES J., 6(2) , 106 (2007)

26. K.-d. A.Wong, K.-w. F. Wong, A. Nadeem, J. Infor. Tech. Const., 467 (2011)

27. T. McCuen, Proceedings of the BIM Academic Symposium 2014, 19 (2014)

28. E. A. Botchway, S. A. Abanyie, S. O. Afram, J. Archit. Eng Tech.4(2), 1(2015)

29. Y. R. Al-Mutri, School of the Built Environment (University of Salford, 2016)K. Ezeji, Journal of Teaching and Education ,281 (2017)

30. J. J. Maina, Int'l Jof Blt Environ. and Sust., 5(3), 175 (2018)M. Hu, Energy and Buildings, 131(2017)

31. T. Kouider, H. Salman, , G. Paterson, 7th Int'l cong. on archit techn., 155 (2018)

32. O. Alagbe, P. Aderonmu, A. Opoko, A. Oluwatayo, O. Dare-Abel, EDULEARN14 Conf, 1588 (2014)

33. C. R. Kothari, Research Methodology: Methods and Techniques (New Age Techno Press, New Delhi, 2012)

34. J. Gill, P. Johnson, M. Clark, Research Methods for Managers (SAGE, London, 2010)

35. H. Taherdoost, Int'l J. Econ. Mgt. Syst., 2, 237 (2017).

36. M. Hamma-Adama, T. Kouidder, 7th Int'l cong. on archit. tech. 87 (2018) 